\title{
Analyzing the Bond Behavior of Fiber-Reinforced Polymer (FRP) Bars Embedded in Engineered Cementitious Composites (ECCs) with the Nonlocal Continuum Rod Model
}

\author{
Qiuxiang Li ${ }^{1},{ }^{1,2}$ Mingfu Fu, ${ }^{1}$ and Banghua Xie ${ }^{2}$ \\ ${ }^{1}$ School of Civil Engineering and Architecture, Nanchang University, Nanchang, Jiangxi 330031, China \\ ${ }^{2}$ School of Civil Engineering and Architecture, Nanchang Institute of Technology, Nanchang, Jiangxi 330099, China \\ Correspondence should be addressed to Qiuxiang Li; 2012994324@nit.edu.cn
}

Received 8 March 2020; Revised 16 May 2020; Accepted 25 June 2020; Published 20 July 2020

Academic Editor: Mitsuhiro Okayasu

Copyright (c) 2020 Qiuxiang Li et al. This is an open access article distributed under the Creative Commons Attribution License, which permits unrestricted use, distribution, and reproduction in any medium, provided the original work is properly cited.

In this study, a nonlocal elastic rod model is applied to analytically evaluate the bond behavior between fiber-reinforced polymer (FRP) bars and engineered cementitious composites (ECCs). The second-order differential equation, which is based on nonlocal elasticity theory, governs the bond behavior of the FRP bars along the bond length. The classical elasticity model is a special case of the nonlocal model. The solution of the second-order differential equation can be obtained by substituting three-stage linear bond stress-slip relationship of the FRP bars. The slip values (solution of the second-order differential equation) within the bond length calculated by the nonlocal continuum rod model are affected by the nonlocal parameter $e_{0} a$. The results from a case study show that the maximum pullout force decreases when the nonlocal size effect is considered, thereby providing a closer approximation of the experimental data than the existing local model.

\section{Introduction}

Fiber-reinforced polymer (FRP) bars are used as an alternative reinforcement for concrete structures due to their high strength, light weight, and high corrosion resistance. Due to the crack bridging effect provided by dispersed fiber reinforcements, engineered cementitious composites (ECCs) feature good postcracking resistance and ductility and sustain multiple stable microcracks during loading; in contrast, major cracks form in normal concrete (NC) during loading [1]. Hence, a combination of the advantages of FRPs and ECCs would be beneficial for construction projects [2-5]. The bond mechanism between FRP bars and ECC is a critical design parameter that controls the performance of FRP/ECC structures at serviceability limit states. Similar to steel bars, the bond behavior of FRP bars is usually presented by a relationship between the shear stress of the bond $(\tau)$ and the relative displacement (slip) between the bar and the matrix. Malvar [6] proposed the first bond-slip constitutive model for GFRP based on many experimental data. Later, the modified Bertero-Eligehausen-Popov (mBEP) model was presented by Cosenza et al. [7] for FRP bars, which adopted the bond-slip constitutive law proposed by Eligehausen et al. [8]. Furthermore, some scholars have updated these models to suit the bond properties of FRP bars in different materials and environments $[9,10]$. In the abovementioned bond-slip relationships, the bond stress is the average bond stress within the bond length zone, and the slip corresponds to the amount of slip at the loaded end or free end. Hence, these relationships represented the overall bond-slip behavior, whereas the influence of the anchoring position is not considered. Mi [11] obtained local bond-slip curves during a pullout experiment by installing a strain probe at different positions that were predrilled inside an FRP bar. Based on the obtained local bond-slip constitutive relationship, the mechanical behavior of the FRP bar was theoretically analyzed and calibrated with the finite element method. Mazaheripour et al. [12] proposed a local bond-slip model with four stages, which they used to calculate the pullout force of FRP bars in steel fiber-reinforced self- 
compacting concrete (SFRSC); they verified the results of their model through a comparison with experimental data. However, there were still some differences between the theoretical calculation results and the experimental results.

Nonlocal elasticity theory [13] is an integrated approach that accounts for characteristic length scale effects and considers the stress at a point in a material as a function of strain within a finite surrounding volume. One of the advantages of this approach is the analysis of uneven stress distributions caused by irregular surfaces and microcracks. Based on this model, many studies have examined the sizedependent effects on the mechanical behavior of bolts [14], anchors [15], rods [16-18], beams [19-21], and plates [22-24]. As shown in $[25,26]$, the stress in the FRP is not evenly distributed within the bond length zone. In addition, the FRP surface has irregularities, cracks, and defects owing to differences in the production processes of different manufacturers and the lack of standardization for surface characteristics. Therefore, these factors can be considered by the nonlocal size effect rather than being ignored or replaced by additional experimental data when analyzing the mechanical behavior of the reinforcement. Hence, there are sufficient reasons to assess the influence of the nonlocal size effect on the mechanical behavior of FRP bars. To the best of the authors' knowledge, no research has been reported on the influence of nonlocal effects on the bond behavior between FRP bars and ECC.

In this study, we confined our attention to the influence of the nonlocal size effect on the bond behavior between FRP bars and ECC. A size-dependent elastic model was developed to analyze the mechanical bond behavior between FRP bars and ECC. Based on nonlocal elasticity theory, the second-order differential equation that governs the bond behavior of the bar along the bond length was derived. The proposed nonlocal model, which combines the three linear bond stress-slip relationships in [11], was used to theoretically analyze the bond behavior of FRP bars with infinite/ finite bond lengths. Finally, an engineering case study was carried out to evaluate the influence of nonlocal size parameters on the slip and pullout force within the bond length of the FRP bars.

\section{Governing Equations of the Nonlocal Elastic Model}

2.1. Nonlocal Continuum Rod Model. Based on classical elastic continuum mechanics, the nonlocal elasticity theory proposed by Eringen and Edelen [27, 28] reveals that the stress field at a desired point can be expressed by a function of the strain field of all points existing in the configuration. Hence, the essence of Eringen's nonlocal theory is the representation of the strains in terms of stresses and stress gradients. Hereinafter, the FRP bar is considered an elastic rod. For a one-dimensional problem in which the longitudinal coordinates are represented by $x$, Eringen's nonlocal constitutive relation can be expressed as [29-31]

$$
\left[1-\left(e_{0} a\right)^{2} \frac{\partial^{2}}{\partial x^{2}}\right] \sigma_{x x}=E \varepsilon_{x x}
$$

where $e_{0}$ is the small length scale coefficient, $a$ is an internal characteristic length (e.g., lattice length or bond length), $\sigma_{x x}$ is the nonlocal axial stress, $\varepsilon_{x x}$ is the axial strain, and $E$ is the longitudinal modulus of elasticity. The nonlocal parameter $e_{0} a$ is introduced to consider the significance of the nonlocal elastic stress field.

2.2. Governing Equations. Before the governing equations can be derived, the following considerations must be taken into account. (1) Within the bond length, the FRP bar exhibits elastic deformation only. In contrast with steel bars, FRP bars have a relatively low Young's modulus and do not have a yielding stage in the stress-strain response, which creates additional challenges in the flexural behavior of concrete members reinforced with FRP bars. To satisfy the requirements for serviceability limit states, FRP bars must exhibit elastic deformation only. (2) In this study, the FRP bars and ECC are considered to be always in contact. The good postcracking resistance and ductility response of the FRP/ECC system results in the formation of multiple stable microcracks during pullout failure, whereas major cracks form in NC. Therefore, only the bond behavior between the FRP bars and ECC during pullout failure is studied. (3) The ECC exhibits and sustains much less deformation than the FRP bars and can therefore be ignored. According to the force diagram of the embedded FRP bar in Figure 1, the relationship between the bond shear stress $\tau$ of the FRP/ECC interface and the axial stress $\sigma_{x x}$ of the bar can be expressed as

$$
\tau(\delta(x)) \pi d \mathrm{~d} x=A\left(\sigma_{x x}+\mathrm{d} \sigma_{x x}\right)-A \sigma_{x x} .
$$

This formula can be further simplified as

$$
\frac{\mathrm{d} \sigma_{x x}}{\mathrm{~d} x}-\frac{4}{d} \tau(\delta(x))=0
$$

where $d$ and $A$ are the diameter and the cross-sectional area of the FRP bar, respectively, and $\delta(x)$ represents the slip between the FRP bar and surrounding ECC at a distance of $x$ from the free end.

By neglecting the deformation of the surrounding concrete, the slip $\delta(x)$ can be represented by an integral of the strain in the FRP bonded segment. The resulting equation can be expressed as

$$
\delta(x)=\delta_{F}+\int \varepsilon_{x x} \mathrm{~d} x,
$$

where $\delta_{F}$ represents the slip between the FRP bar and surrounding ECC at the free end.

Using equations (1)-(4), a governing equation for the bond behavior along the bond length in the nonlocal elastic model can be found in terms of slip. This equation is expressed as 


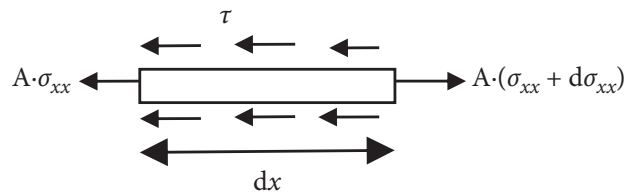

FIGURE 1: Force diagram of the FRP bar.

$$
\frac{\partial^{2} \delta(x)}{\partial x^{2}}-J \cdot\left[1-\left(e_{0} a\right)^{2} \frac{\partial^{2}}{\partial x^{2}}\right] \cdot \tau(\delta(x))=0,
$$

where $J=4 / E d$. Equation (5) is a fundamental equation in the nonlocal rod model that represents the bond behavior along the bond length of the FRP bar. When $e_{0} a=0$, equation (5) degenerates into the classical elastic model shown in $[11,12]$.

\section{Bond Stress-Slip Relationship}

In [11], twenty pullout experiments were performed with round/ribbed deformation FRP (carbon FRP (CFRP) and glass FRP (GFRP)) bars, and a three-stage linear relationship was obtained from the results, as shown in Figure 2. This relationship is used as the bond shear stress-slip $(\tau-\delta)$ relationship between the FRP bars and ECC in this study. This $\tau-\delta$ relationship can be divided into three stages: an elastic stage, a softening stage, and a frictional stage. These stages are described hereinafter:

$$
\tau(\delta(x))= \begin{cases}\tau_{0}+\frac{\tau_{m}-\tau_{0}}{\delta_{1}} \delta, & 0 \leq \delta \leq \delta_{1} \text { (elastic), } \\ \tau_{m}-\frac{\tau_{m}-\tau_{f}}{\delta_{2}-\delta_{1}}\left(\delta-\delta_{1}\right), & \delta_{1} \leq \delta \leq \delta_{2} \text { (softening), } \\ \tau_{f}, & \delta \geq \delta_{2} \text { (frictional). }\end{cases}
$$

To account for the chemical and micromechanical properties of the materials and interfaces involved in this study, a horizontal segment is used at the beginning of the curve $\left(0-\tau_{0}\right)$ to represent the initial shear stress before relative sliding occurs between the FRP bar and ECC. The elastic stage represents the portion of the curve in which the shear stress increases from the initial bond shear stress $\left(\tau_{0}\right)$ to the bond stress at a slip of $\delta_{1}\left(\tau_{m}\right)$. As damage accumulates in the bar/concrete interface, the bond stress starts decreasing as slip increases. This softening stage, which is attributed to friction and micromechanical interlocking along the length of the bond, is represented by the branch of the curve that ends at a slip of $\delta_{2}$; the residual bond shear stress $\left(\tau_{f}\right)$ is found at this point. For $\delta>\delta_{2}$, the bond stress is constant due to the friction between the FRP bar and ECC.

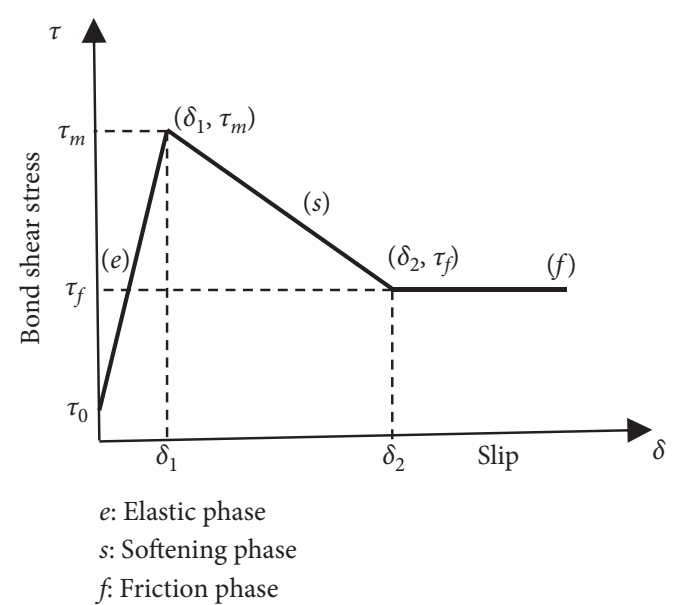

FIGURE 2: Bond shear stress-slip relationship.

\section{Theoretical Pullout Force of FRP Bars with Infinite/Finite Bond Lengths Based on the Nonlocal Model}

4.1. Theoretical Analysis with Infinite Bond Length. If the bond length of the FRP embedded in the ECC is infinite, the pullout process can be described by introducing the proposed $(\tau-\delta)$ relationship in equation (6) into equation (5). Note that $\delta(x)$ denotes the slip distribution along the bar, $L_{\mathrm{tr}}\left(\delta_{L}\right)$ denotes the required bond transfer length, and $F(x)$ represents the pullout forces in each section of the bar, which are determined for specific values of slip at the loaded end $\delta_{L}$. These concepts and the definition of the local reference systems in the elastic $\left(x^{e}\right)$, softening $\left(x^{s}\right)$, and frictional $\left(x^{f}\right)$ bond stages which are illustrated in Figure 3.

4.1.1. Elastic Stage. When the slip at the loaded end is $0 \leq \delta_{L} \leq \delta_{1}$, equation (5) is solved in the local reference system of $x^{e}$, and the solution becomes [12]

$$
\delta^{e}\left(x^{e}\right)=C_{1}^{e} e^{\lambda x}+C_{2}^{e} e^{-\lambda x}-C_{3}^{e},
$$

where $1 / \lambda^{2}=\delta_{1}+J\left(e_{0} a\right)^{2}\left(\tau_{m}-\tau_{0}\right) / J\left(\tau_{m}-\tau_{0}\right)$.

Note that the particular solution of equation (5) is

$$
C_{3}^{e}=\frac{\delta_{1} \tau_{0}}{\tau_{m}-\tau_{0}} .
$$

This solution was obtained by imposing the following boundary conditions on equation (7):

$$
\begin{array}{r}
\delta^{e}=0 \text { at } x^{e}=0, \\
\delta^{e}=\delta_{L} \text { at } x^{e}=L_{\text {tr }}^{e}\left(\delta_{L}\right),
\end{array}
$$

where $L_{\mathrm{tr}}^{e}\left(\delta_{L}\right)$ is the bond transfer length corresponding to the elastic stage $\left(\delta_{L} \leq \delta_{1}\right)$. The integration constants can be obtained as 


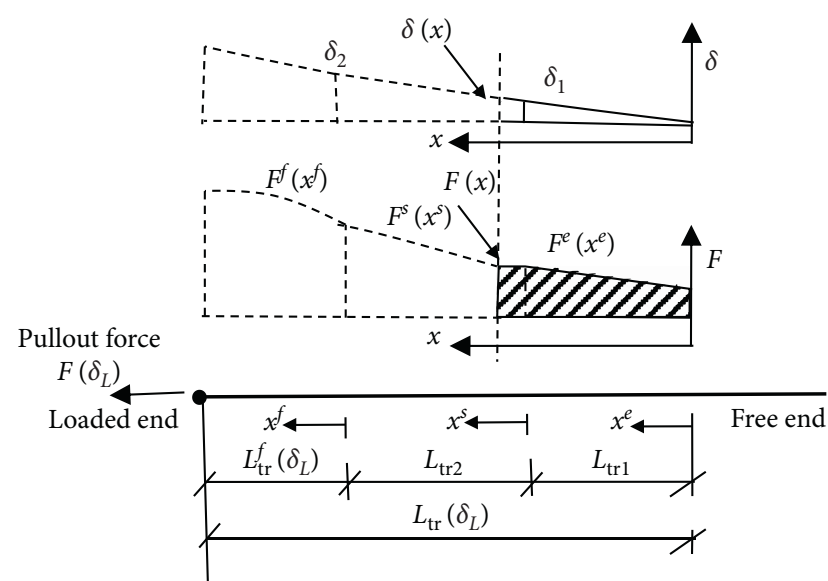

FIgURe 3: Pullout process of an FRP bar with an infinite bond length (definition of local reference systems).

$$
\begin{aligned}
& C_{1}^{e}=\left[\delta_{L}+C_{3}^{e}\left(1-e^{-\lambda L_{\mathrm{tr}}^{e}\left(\delta_{L}\right)}\right)\right] \cdot \frac{1}{e^{\lambda L_{\mathrm{tr}}^{e}\left(\delta_{L}\right)}-e^{-\lambda L_{\mathrm{tr}}^{e}\left(\delta_{L}\right)}}, \\
& C_{2}^{e}=C_{3}^{e}-C_{1}^{e} .
\end{aligned}
$$

The equilibrium equation was imposed along the bond length, i.e., $F\left[x=L_{\mathrm{tr}}\left(\delta_{L}\right)\right]=\pi d \cdot \int_{0}^{L_{\mathrm{tr}}\left(\delta_{L}\right)} \tau\left(x^{e}\right) \mathrm{d} x^{e}$. Hence, $L_{\mathrm{tr}}^{e}\left(\delta_{L}\right)$ can be calculated by

$$
L_{\mathrm{tr}}^{e}\left(\delta_{L}\right)=\frac{1}{\lambda} \operatorname{arcosh}\left(1+\frac{\delta_{L}}{C_{e}^{3}}\right)
$$

Moreover, the pullout force at a certain value of imposed slip can be obtained as

$$
\begin{aligned}
& F\left[x=L_{\mathrm{tr}}\left(\delta_{L}\right)\right]=F^{e}\left[x=L_{\mathrm{tr}}^{e}\left(\delta_{L}\right)\right] \\
& =\pi \mathrm{d} \int_{0}^{L_{e}^{\mathrm{tr}}\left(\delta_{L}\right)} \tau\left(x^{e}\right) \mathrm{d} x^{e}=\left.\mathrm{EA}\left(\frac{\mathrm{d} \delta^{e}}{\mathrm{~d} x^{e}}\right)\right|_{0} ^{L_{\mathrm{tr}}^{e}}\left(\delta_{L}\right) .
\end{aligned}
$$

Then, the maximum bond transfer length $\left(L_{\mathrm{tr} 1}\right)$ and maximum pullout force $\left(F_{e}^{1}\right)$ in the elastic stage can be determined by imposing a loaded end slip of $\delta_{1}$ :

$$
\begin{aligned}
& L_{\mathrm{tr} 1}=L_{\mathrm{tr}}^{e}\left(\delta_{L}=\delta_{1}\right), \\
& F_{1}^{e}=F^{e}\left(x^{e}=L_{\mathrm{tr} 1}\right) .
\end{aligned}
$$

4.1.2. Softening Stage. When the imposed slip is $\delta_{1} \leq \delta_{L} \leq \delta_{2}$, the process has entered the second stage. After introducing the appropriate function from equation (6) into equation (5), the solution in the local coordinate system of $x^{s}$ is expressed as [12]

$$
\delta^{s}\left(x^{s}\right)=C_{1}^{s} \cdot \sin \left(\kappa \cdot x^{s}\right)+C_{2}^{s} \cdot \cos \left(\kappa \cdot x^{s}\right)+C_{3}^{s},
$$

with

$$
\kappa^{2}=J\left(\tau_{m}-\tau_{f}\right) /\left(\delta_{2}-\delta_{1}\right) / 1+\left(e_{0} a\right)^{2} J\left(\tau_{m}-\tau_{f}\right) /
$$

$\left(\delta_{2}-\delta_{1}\right)$

Therefore, if $\beta^{2}=J\left(\tau_{m}-\tau_{f}\right) / \delta_{2}-\delta_{1}$, the particular solution of the differential equation becomes

$$
C_{3}^{s}=\frac{J \tau_{m}}{\beta^{2}}+\delta_{1}
$$
were

The boundary conditions used in the softening stage

$$
\begin{aligned}
& \delta^{s}=\delta_{1} \text { at } x^{s}=0, \\
& \delta^{s}=\delta_{L} \text { at } x^{s}=L_{\text {tr }}^{s}\left(\delta_{L}\right),
\end{aligned}
$$

where $L_{\mathrm{tr}}^{s}\left(\delta_{L}\right)$ is the bond transfer length in the softening stage $\delta_{1} \leq \delta_{L} \leq \delta_{2}$. The integration constants can be obtained as

$$
C_{1}^{s}=\frac{1}{\sin \left(\kappa \cdot L_{\mathrm{tr}}^{s}\left(\delta_{L}\right)\right)} \cdot\left\{\delta_{L}-\delta_{1}+\frac{J \tau_{m}}{\beta^{2}} \cdot\left[\cos \left(\kappa \cdot L_{\mathrm{tr}}^{s}\right)-1\right]\right\},
$$

$C_{2}^{s}=\delta_{1}-C_{3}^{s}=-\frac{J \tau_{m}}{\beta^{2}}$

The equilibrium condition was imposed along the bond length, i.e., $F\left[x=L_{\mathrm{tr}}\left(\delta_{L}\right)\right]=\pi d \cdot \int_{0}^{L_{\mathrm{tr}}^{s}\left(\delta_{L}\right)} \tau\left(x^{s}\right) \mathrm{d} x^{s}+F_{1}^{e}$, to derive the bond transfer length as a function of $\delta_{L}$. Note that $L_{\mathrm{tr}}^{s}\left(\delta_{L}\right)$ can be expressed as [12]

$$
L_{\mathrm{tr}}^{s}\left(\delta_{L}\right)=\frac{1}{\kappa} \cdot\left[\arcsin \left(\frac{B_{s}}{\sqrt{D_{s}^{2}+B_{s}^{2}}}\right)+\arcsin \left(\frac{C_{s}}{\sqrt{D_{s}^{2}+B_{s}^{2}}}\right)\right],
$$

where $B_{s}=\pi d \cdot \tau_{m} / \kappa$

$$
\begin{aligned}
& C_{s}=\frac{\pi d \cdot \kappa}{J} \cdot\left(\delta_{L}-C_{3}^{s}\right), \\
& D_{s}=F_{1}^{e} .
\end{aligned}
$$

The overall bond transfer length at the end of the softening stage is

$$
L_{\mathrm{tr}}\left(\delta_{L}\right)=L_{\mathrm{tr} 1}+L_{\mathrm{tr}}^{s}\left(\delta_{L}\right) .
$$

Moreover, the pullout force for a particular value of imposed slip in this stage can be calculated as

$$
F^{s}\left[x=L_{\mathrm{tr}}^{s}\left(\delta_{L}\right)\right]=\pi d \int_{0}^{L_{\mathrm{tr}}^{s}\left(\delta_{L}\right)} \tau\left(x^{s}\right) \mathrm{d} x^{s}=\left.\operatorname{EA}\left(\frac{\mathrm{d} \delta^{s}}{\mathrm{~d} x^{s}}\right)\right|_{0} ^{L_{\mathrm{tr}}^{s}\left(\delta_{L}\right)}
$$

Hence, the total pullout force becomes

$$
F\left[x=L_{\mathrm{tr}}\left(\delta_{L}\right)\right]=F_{1}^{e}+F^{s}\left[x^{s}=L_{\mathrm{tr}}^{s}\left(\delta_{L}\right)\right] .
$$

The maximum bond transfer length and maximum pullout force in this stage can also be calculated by imposing $\delta_{L}$ equal to $\delta_{2}$ in equations (21) and (24), respectively:

$$
\begin{gathered}
L_{\mathrm{tr} 2}=L_{\mathrm{tr}}^{s}\left(\delta_{L}=\delta_{2}\right), \\
F_{2}^{s}=F^{s}\left(x^{s}=L_{\mathrm{tr} 2}\right) .
\end{gathered}
$$

The total force at the end of the softening stage becomes

$$
F_{2}=F\left[x=L_{\mathrm{tr}}\left(\delta_{L}=\delta_{2}\right)\right]=F_{1}^{e}+F_{2}^{\mathcal{s}} .
$$


4.1.3. Frictional Stage. The frictional stage corresponds to the range in which the slip at the loaded end $\delta_{L} \geq \delta_{2}$. In this stage, the bond shear stress is a constant value $\tau_{f}$ because a stable amount of interfacial friction is generated between the FRP bar and the surrounding ECC. Therefore, the solution of equation (5) is a polynomial function in the local reference system of $x^{s}$, which can be expressed as

$$
\delta^{f}\left(x^{f}\right)=C_{1}^{f}\left(x^{f}\right)^{2}+C_{2}^{f} x^{f}+C_{3}^{f} .
$$

Note that

$$
C_{1}^{f}=\frac{J \tau_{f}}{2}
$$

and the boundary conditions are

$$
\begin{aligned}
& \delta^{f}=\delta_{2} \text { at } x^{f}=0, \\
& \delta^{f}=\delta_{L} \text { at } x^{f}=L_{\text {tr }}^{f}\left(\delta_{L}\right),
\end{aligned}
$$

where $L_{\mathrm{tr}}^{f}\left(\delta_{L}\right)$ is the bond transfer length for $\delta_{L}>\delta_{2}$. By imposing these boundary conditions on equation (29), the integration constants can be expressed as

$$
\begin{aligned}
& C_{2}^{f}=\frac{\left(\delta_{L}-\delta_{2}\right)-C_{1}^{f}\left[L_{\mathrm{tr}}^{f}\left(\delta_{L}\right)\right]^{2}}{L_{\mathrm{tr}}^{f}\left(\delta_{L}\right)}, \\
& C_{3}^{f}=\delta_{2} .
\end{aligned}
$$

Using the equilibrium equation, i.e., $F\left[x=L_{\mathrm{tr}}\left(\delta_{L}\right)\right]=$ $\pi d \cdot \int_{0}^{L_{\mathrm{tr}}^{f}\left(\delta_{L}\right)} \tau\left(x^{f}\right) \mathrm{d} x^{f}+F_{2}^{s}+F_{1}^{e}, L_{\mathrm{tr}}^{f}\left(\delta_{L}\right)$ can be expressed as

$$
L_{\mathrm{tr}}^{f}\left(\delta_{L}\right)=\frac{F_{2}^{s}-\left[F_{2}^{s}+4 C_{1}^{f}\left(\delta_{L}-\delta_{2}\right)\right]^{0.5}}{2 C_{1}^{f}}
$$
from

The pullout force for any value of $\delta_{L}>\delta_{2}$ can be obtained

$$
F^{f}\left[x=L_{\mathrm{tr}}^{f}\left(\delta_{L}\right)\right]=\pi d \int_{0}^{L_{\mathrm{tr}}^{f}\left(\delta_{L}\right)} \tau_{f} \mathrm{~d} x^{f}=\pi d \cdot L_{\mathrm{tr}}^{f}\left(\delta_{L}\right) \cdot \tau_{f} .
$$

The total pullout force is

$$
F\left[x=L_{\mathrm{tr}}\left(\delta_{L}\right)\right]=F_{1}^{e}+F_{2}^{s}+F^{f}\left[x^{f}=L_{\mathrm{tr}}^{f}\left(\delta_{L}\right)\right] .
$$

4.2. Theoretical Analysis with Finite Bond Length. From the analysis presented in Section 4.1, in the case of infinite bond length, the pullout process of an embedded FRP bar in ECC can be analyzed by substituting the bond stress-slip relationship into equation (5) and imposing boundary conditions for slip at the end of the bond transfer length $\left(L_{t r}\right)$. However, when the embedded FRP has a finite bond length, the analysis needs to be discussed. When the finite bond length $\left(L_{f}\right)$ exceeds the bond transfer length, the pullout force for any value of $\delta_{L}$ can be directly calculated with equations (15), (25), and (36), similar to the approach used with an infinite bond length. However, when $\delta_{F}>0$, i.e., $L_{f}<L_{\mathrm{tr}}$, two or more bond-slip stages occur simultaneously within $L_{f}$, and calculating pullout force $F$ is not straightforward due to the complexity of the expression. Bianco et al. [32] and Mazaheripour et al. [12] verified that the slip distribution $(\delta(x))$ for infinite bond length conditions could also be applied to finite bond length conditions. This means that the expression of $(\delta(x))$ is the same in both cases; however, different boundary conditions are used in these two cases.

The next study is based on the works carried out by Mazaheripour et al. [12] on SFRSC beams reinforced with GFRP bars. The pullout force $(F)$ in the case of a finite bond length $\left(L_{f}\right)$ is determined for any value of $\delta_{L}$ by substituting a variable boundary that does not impose the same bond transfer length $L_{\mathrm{tr}}\left(\delta_{L}\right)$ corresponding to any complete stage. Therefore, for each bond stage, new integration constants in equations (7), (16), and (29) are under the conditions at the free and loaded ends (i.e., $\delta=\delta_{F}$ at $x=0$ and $\delta=\delta_{L}$ at $\left.x=L_{f}\right)$. Then, a new $\delta(x)$ can be calculated over $L_{f}$. Finally, the pullout force $F$ and the slip at the free end $\delta_{F}$ can be determined by considering different configurations of the proposed bond stages over the bond length.

\subsubsection{Only One Bond Stage Acting on $L_{f}$}

(1) Elastic Stage Only (Figure 4(a)). When $\delta_{L} \leq \delta_{1}$ and $0<\delta_{F}<\delta_{1}$, the elastic stage is the only bond stage acting on $L_{f}$. Accordingly, equations (10) and (11) become

$$
C_{1}^{e}=\left[\left(\delta_{L}-\delta_{F} e^{-\lambda L_{f}}\right)+C_{3}^{e} \cdot\left(1-e^{-\lambda L_{f}}\right)\right] \cdot \frac{1}{e^{\lambda L_{f}}-e^{-\lambda L_{f}}},
$$

$C_{2}^{e}=\left(\delta_{F}+C_{3}^{e}\right)-C_{1}^{e}$ $\delta_{L}$

Using the equilibrium conditions, $\delta_{F}$ can be expressed by

$$
\delta_{F}=\frac{\delta_{L}+C_{3}^{e}}{\cosh \left(\lambda L_{f}\right)}-C_{3}^{e}
$$

The pullout force can then be calculated by equations (37) and (38):

$$
\begin{aligned}
F^{e}\left(x^{e}=L_{f}\right)= & A \sigma_{x x}\left(x^{e}=L_{f}\right)=\mathrm{EA} \cdot\left[C_{1}^{e}\left(\delta_{L}\right) \cdot \lambda e^{\lambda L_{f}}\right. \\
& \left.-C_{2}^{e}\left(\delta_{L}\right) \cdot \lambda e^{-\lambda L_{f}}\right] .
\end{aligned}
$$

(2) Softening Stage Only (Figure 4(b)). When $\delta_{F}>\delta_{1}$ and $\delta_{L} \leq \delta_{2}$, the softening stage is the only bond stage acting on $L_{f}$. The integration constants in equations (19) and (20) can be expressed as

$$
\begin{aligned}
& C_{1}^{s}=\frac{1}{\sin \left(\kappa \cdot L_{f}\right)} \cdot\left\{\delta_{L}-\delta_{F}+\frac{J \cdot \tau_{m}}{\beta^{2}} \cdot\left[\cos \left(\kappa \cdot L_{f}\right)-1\right]\right\} \\
& C_{2}^{s}=\delta_{F}-C_{3}^{s} .
\end{aligned}
$$

Then, $\delta_{F}$ can be expressed as a function of $\delta_{L}$ with the equilibrium condition: 


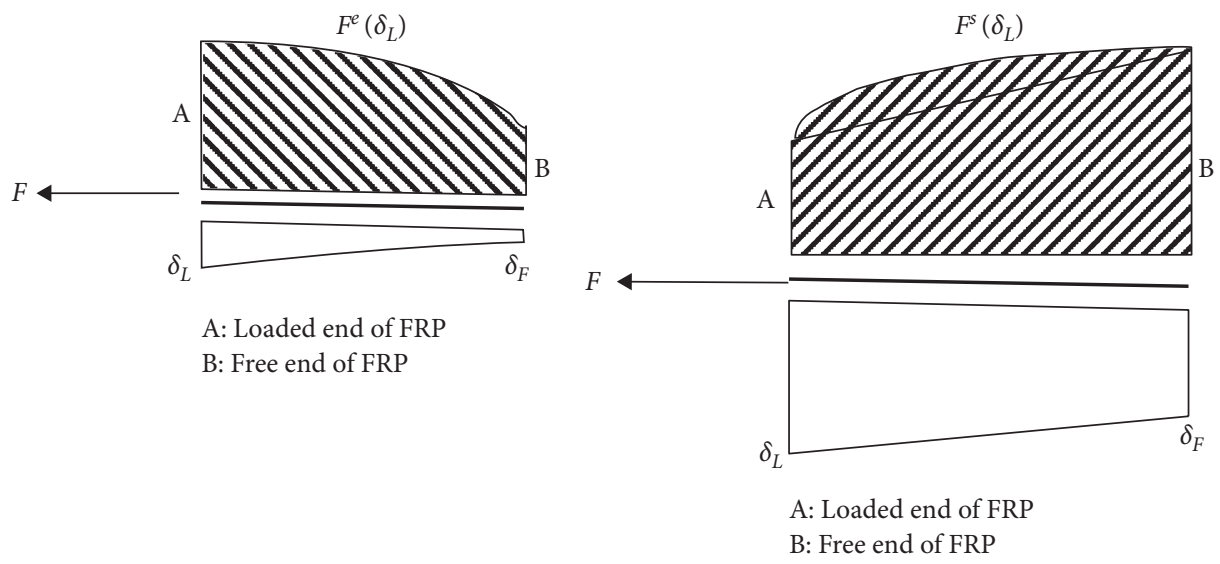

(a)

(b)

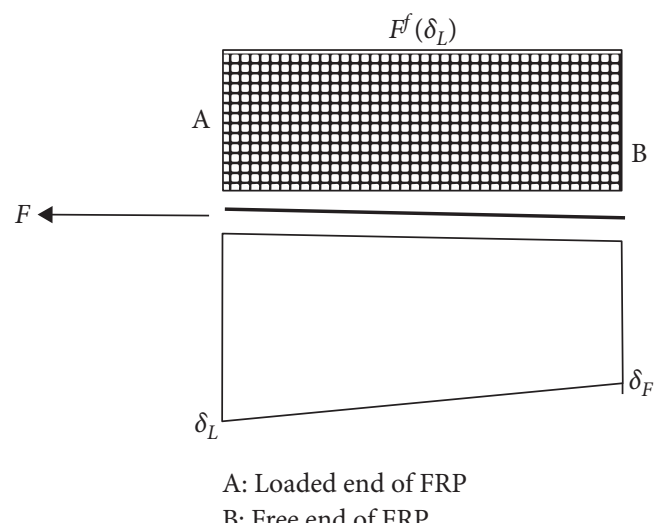

(c)

Figure 4: Configurations of $F(x)$ and $\delta(x)$ when only one bond stage is acting on $L_{f}$ : (a) elastic stage only, (b) softening stage only, and (c) frictional stage only.

$$
\delta_{F}=\delta_{L}-\frac{J \cdot \tau_{m}}{\beta^{2}} \cos \left(\kappa \cdot L_{f}\right)+\left(C_{3}^{s}-\delta_{1}\right) .
$$

Therefore, $F$ in this stage can be obtained from equations (41) and (42):

$$
F^{s}\left(x^{s}=L_{f}\right)=\pi d \int_{0}^{L_{f}} \tau\left(x^{s}\right) \mathrm{d} x^{s}=\left.\mathrm{EA}\left(\frac{\mathrm{d} \delta^{s}}{\mathrm{~d} x^{s}}\right)\right|_{0} ^{L_{f}} .
$$

(3) Frictional Stage Only (Figure 4(c)). When $\delta_{L}>\delta_{2}$ and $\delta_{F}>\delta_{2}$, the friction stage is the only bond stage acting on $L_{f}$. The integration constants in equations (32) and (33) can be expressed as

$$
\begin{aligned}
C_{2}^{f} & =\frac{\left(\delta_{L}-\delta_{F}\right)-C_{1}^{f}\left(L_{f}\right)^{2}}{L_{f}}, \\
C_{3}^{f} & =\delta_{F} .
\end{aligned}
$$

Then, $\delta_{F}$ can be obtained by

$$
\delta_{F}=\delta_{L}-C_{1}^{f}\left(L_{f}\right)^{2}
$$

Moreover, $F$ can be obtained by

$$
F^{f}\left(x^{f}=L_{f}\right)=L_{f} \pi \mathrm{d} \tau_{f} .
$$

4.2.2. Two or More Bond Stages Acting on $L_{f}$. In the present study, when two or more bond stages are acting on $L_{f}$, a numerical strategy is adopted to obtain the slip and force (or bond stress) distributions. Hence, by taking a small increment in the imposed slip at the ith step of the calculation (i.e., $\delta_{L}^{i}=\delta_{L}^{i-1}+\Delta \delta_{L}$ ) and initially using the value of the pullout force at the last converged step of the calculation $(i-1)$, for each bond stage (i.e., $\left(F^{e}\right)^{i-1},\left(F^{s}\right)^{i-1}$ and $\left.\left(F^{f}\right)^{i-1}\right)$, a new value of the pullout force $\left(F^{i}=F^{i-1}+\Delta F\right)$ can be calculated.

(1) Both Elastic and Softening Stages Acting on $L_{f}$ (Figure $5(a))$. For $\delta_{L}^{i},\left(L_{\text {tr }}^{s}\right)^{i}$ can be calculated by equation (21), where $F_{1}^{e}$ is replaced by $\left(F^{e}\right)^{i-1}$. When obtaining $\left(L_{\mathrm{tr}}^{s}\right)^{i},\left(L_{\mathrm{tr}}^{e}\right)^{i}$ is simply derived from $L_{f}-\left(L_{\mathrm{tr}}^{s}\right)^{i}$. Therefore, $\left(\delta_{F}\right)^{i}$ and $\left(F^{e}\right)^{i}$ can be calculated by equations (39) and (40), respectively, at $x^{e}=\left(L_{\mathrm{tr}}^{e}\right)^{i} .\left(F^{s}\right)^{i}$ can also be calculated from equation $(44)$ at $x^{s}=\left(L_{\text {tr }}^{s}\right)^{i}$. The total pullout force becomes

$$
F^{i}=\left(F^{e}\right)^{i}+\left(F^{s}\right)^{i} .
$$




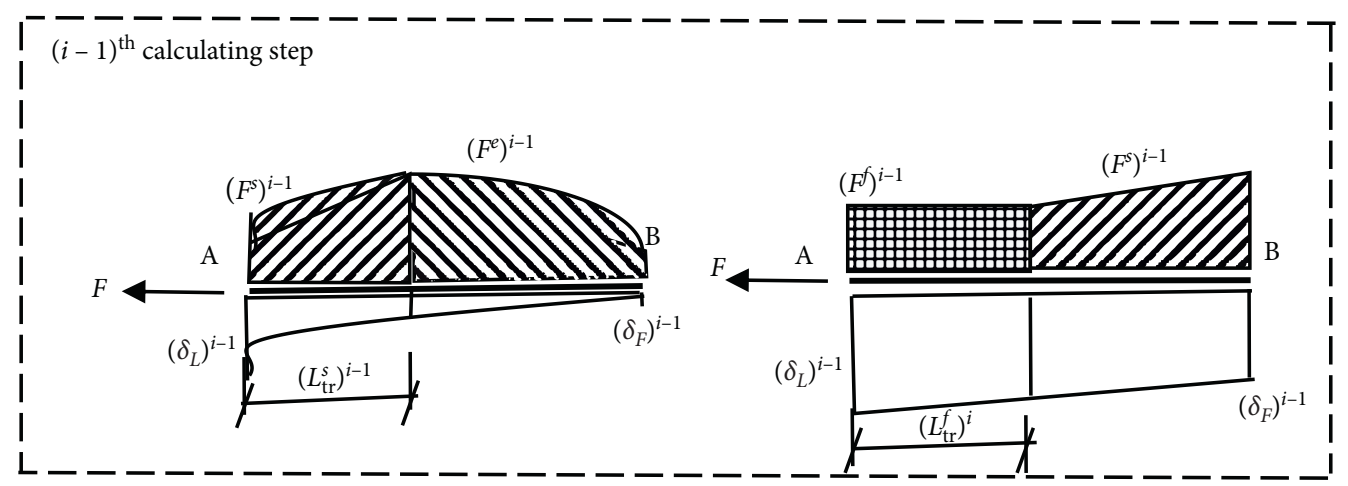

(a)

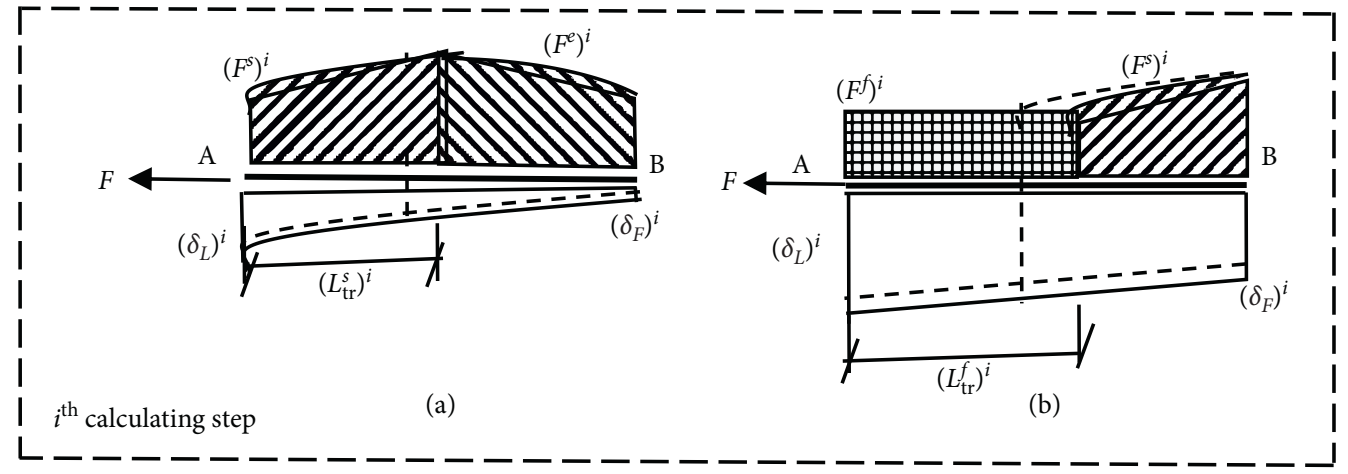

(b)

Figure 5: Configurations for $F(x)$ and $\delta(x)$ when two bond stages are acting on $L_{f}$ : (a) both elastic and softening stages and (b) both softening and frictional stages.

(2) Both Softening and Frictional Bond Stages Acting on $L_{f}$ (Figure $5(b)$ ). For $\delta_{L}^{i},\left(L_{\text {tr }}^{f}\right)^{i}$ can be calculated by means of equation (34), where $F_{1}^{e}$ is null and $F_{2}^{s}$ is substituted by $\left(F^{s}\right)^{i-1}$. When obtaining $\left(L_{\mathrm{tr}}^{f}\right)^{i},\left(L_{\mathrm{tr}}^{s}\right)^{i}$ is derived by $L_{f}-\left(L_{\mathrm{tr}}^{f}\right)^{i}$. Therefore, $\left(\delta_{F}\right)^{i}$ and $\left(F^{s}\right)^{i}$ can be calculated by equations (43) and (44), respectively, at $x^{s}=\left(L_{\mathrm{tr}}^{s}\right)^{i} ;\left(F^{f}\right)^{i}$ can also be calculated from equation (48) at $x^{f}=\left(L_{\text {tr }}^{f}\right)^{i}$. The total pullout force becomes

$$
F^{i}=\left(F^{s}\right)^{i}+\left(F^{f}\right)^{i}
$$

(3) Elastic, Softening, and Frictional Stages Acting on $L_{f}$ (Figure 6). When $\delta_{L}>\delta_{2}$ and $\left(L_{f}>L_{\text {tr }}\left(\delta_{L}\right)\right)$, the three proposed bond stages occur simultaneously within $L_{f}$. By imposing a small increment in $\delta_{L}$, the same strategy can also be applied in this case to determine $\left(L_{\mathrm{tr}}^{s}\right)^{i}$ and $\left(L_{\mathrm{tr}}^{f}\right)^{i}$ by initially taking $F_{1}^{e}$ and $F_{2}^{s}$ as $\left(F^{e}\right)^{i-1}$ and $\left(F^{s}\right)^{i-1}$, respectively. Then, $\left(L_{\mathrm{tr}}^{e}\right)^{i}$ can be obtained by

$$
\left(L_{\mathrm{tr}}^{e}\right)^{i}=L_{f}-\left(L_{\mathrm{tr}}^{s}\right)^{i}-\left(L_{\mathrm{tr}}^{f}\right)^{i} .
$$

Hence, the total pullout force can be expressed as

$$
F^{i}=\left(F^{e}\right)^{i}+\left(F^{s}\right)^{i}+\left(F^{f}\right)^{i}
$$

A flowchart of the proposed analytical-numerical algorithm is presented in Figure 7. In all of the above cases, once $\left(L_{\mathrm{tr}}\right)^{i}$ is obtained for all active bond stages (e.g., the

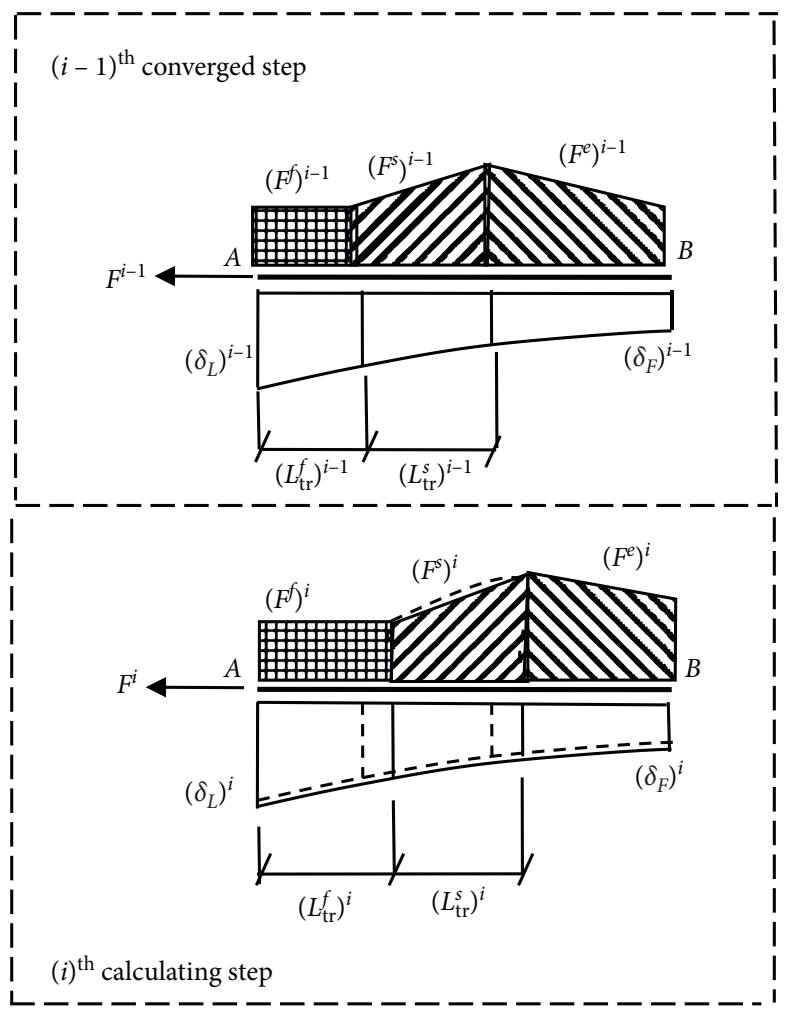

Figure 6: Configurations for $F(x)$ and $\delta(x)$ when the elastic, softening, and frictional stages are simultaneously acting on $L_{f}$. 

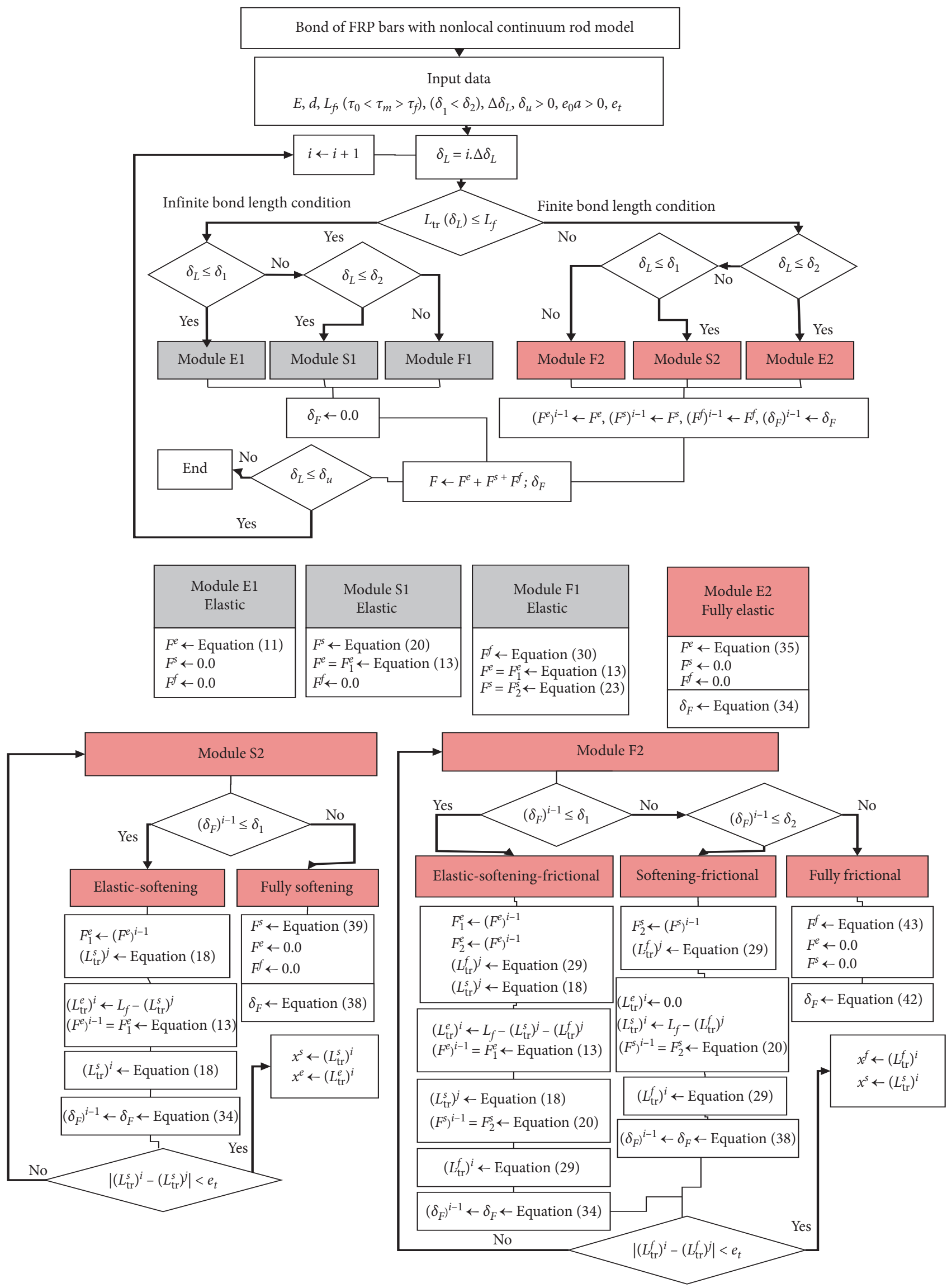

FigURE 7: Flowchart of the nonlocal continuum rod model. 
TABLE 1: Values of the parameters and experimental results.

\begin{tabular}{lcccccccccccc}
\hline \multirow{2}{*}{ Specimens } & \multicolumn{1}{c}{ Parameters } & \multicolumn{4}{c}{ Experimental results } \\
& $E_{c}(\mathrm{GPa})$ & $E_{s}(\mathrm{GPa})$ & $d_{s}(\mathrm{~mm})$ & $b(\mathrm{~mm})$ & $L_{f}(\mathrm{~mm})$ & $\tau_{0}(\mathrm{MPa})$ & $\tau_{m}(\mathrm{MPa})$ & $\tau_{f}(\mathrm{MPa})$ & $\delta_{1}(\mathrm{~mm})$ & $\delta_{2}(\mathrm{~mm})$ & $F_{\mathrm{max}}(\mathrm{kN})$ & $F_{\text {res }}(\mathrm{kN})$ \\
\hline C30 & 30 & 180.1 & 10 & 100 & 100 & 0.03 & 1 & 0.72 & 0.55 & 2.43 & 2.94 \\
G50 & 30 & 32 & 10 & 100 & 100 & 0.14 & 0.74 & 0.46 & 0.61 & 3.84 & 2.28 \\
\hline
\end{tabular}

Note. C30 represents the specimens containing CFRP bars embedded in ECC with a compressive strength of $30 \mathrm{MPa}$, whereas G50 represents the specimens containing GFRP bars embedded in ECC with a compressive strength of $50 \mathrm{MPa}$.

elastic, plastic, and softening stages are all active for the case shown in Figure 5(a)), the values of $\left(F^{e}\right)^{i-1},\left(F^{s}\right)^{i-1}$, and $\left(F^{f}\right)^{i-1}$ are replaced by the new calculated values of $\left(F^{e}\right)^{i},\left(F^{s}\right)^{i}$, and $\left(F^{f}\right)^{i}$, respectively. Then, $\left(L_{\mathrm{tr}}\right)^{i}$ is recalculated until the error becomes less than the tolerance adopted for $\Delta L_{\text {tr }}$. This calculation loop is also illustrated in the flowchart.

\section{Case Study and Discussion}

To illustrate the bond behavior with the nonlocal elastic model, FRP bars embedded in ECC were subjected to pullout tests in [11]. The parameters and experimental results are shown in Table 1. The maximum pullout forces calculated using the classical elastic model for CFRP bars and GFRP bars were $3.09 \mathrm{kN}$ and $2.30 \mathrm{kN}$, respectively. We confined our attention to the influence of the nonlocal parameter $e_{0} a$ on $\delta(x)$ and the pullout force $F$ with a finite bond length $L_{f}$.

5.1. Introduction of Free-End Slip $\delta_{F}$ to the Nonlocal Elastic Model. As shown in Section 4.2, when the FRP bar only experiences one bond stage, the slip at the free end $\delta_{F}$ can be determined by equations (39), (43), and (47) for any value of imposed slip in the case of finite bond length. A comparison of the nonlocal elastic model and the classical elastic model shows that the free-end slip exhibits differences when the FRP bar experiences different debonding processes, as shown in Figures 8-10.

Note that $\delta_{F}\left(e_{0} a\right)$ is the free-end slip under the nonlocal elastic model, whereas $\delta_{F}$ is the free-end slip under the classical elastic model. In the elastic stage (Figure 8), due to the nonlocal size effect, the free-end slip is slightly larger in the nonlocal elastic model than in the classical elastic model, and the growth trend is positively related to the nonlocal parameter $e_{0} a$ and inversely related to the slip at the loaded end $\delta_{L}$. The nonlocal effect within the elastic stage is more obvious in the early portion of the stage. For the softening stage in Figure 9, the free-end slip under the nonlocal elastic model decreases as the nonlocal parameter increases. This trend is more significant with a small value of imposed slip $\delta_{L}$. For the frictional stage in Figure 10, the free-end slip is not affected by the nonlocal parameters because the constant stress field does not depend upon the nonlocal parameter $e_{0} a$ (as confirmed by Benvenuti and Simone [33]).

Nonlocal effects affect the slip $\delta(x)$ over $L_{f}$ in the elastic and softening stages. Therefore, the maximum pullout force, which only appears in the first two stages of the debonding process, needs further analysis.

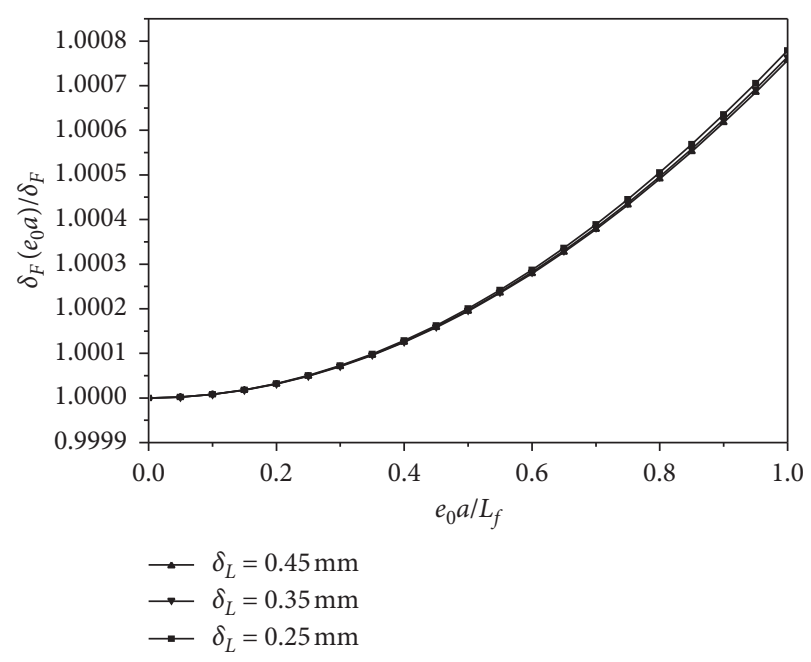

FIGURE 8: Normalized free-end $\operatorname{slip} \delta_{F}\left(e_{0} a\right)$ for various values of $e_{0} a / L_{f}$ and representative values of $\delta_{L}$ when the elastic stage was the only bond stage acting on the FRP bar.

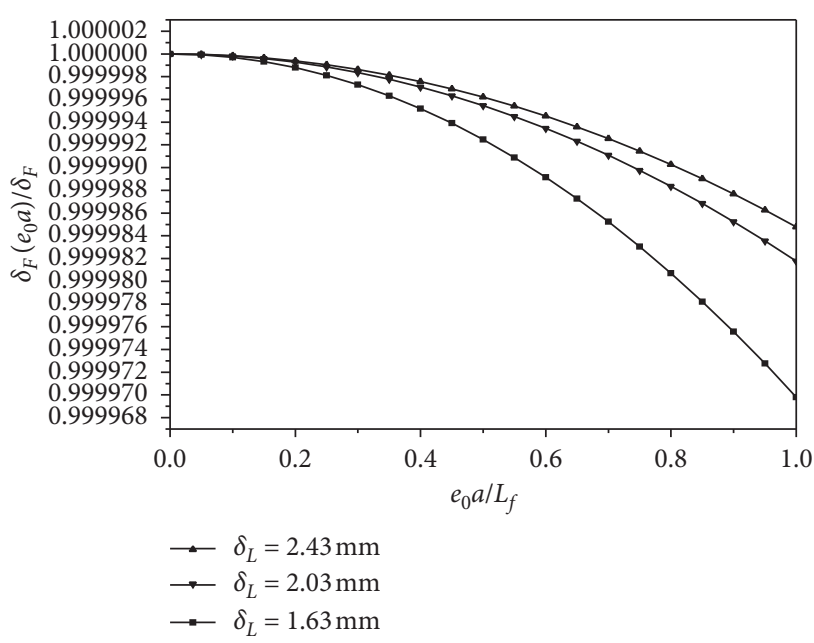

FIgURE 9: Normalized free-end $\operatorname{slip} \delta_{F}\left(e_{0} a\right)$ for various values of $e_{0} a / L_{f}$ and representative values of $\delta_{L}$ when the softening stage was the only bond stage acting on the FRP bar.

5.2. Analysis of the Pullout Force F. The pullout force-loaded end slip curve based on the nonlocal elastic model is similar to that in the classical elastic model; however, the curve based on the nonlocal model is closer to the experimental values due to the influence of the nonlocal effects. The pullout force-slip relationship recorded from the 


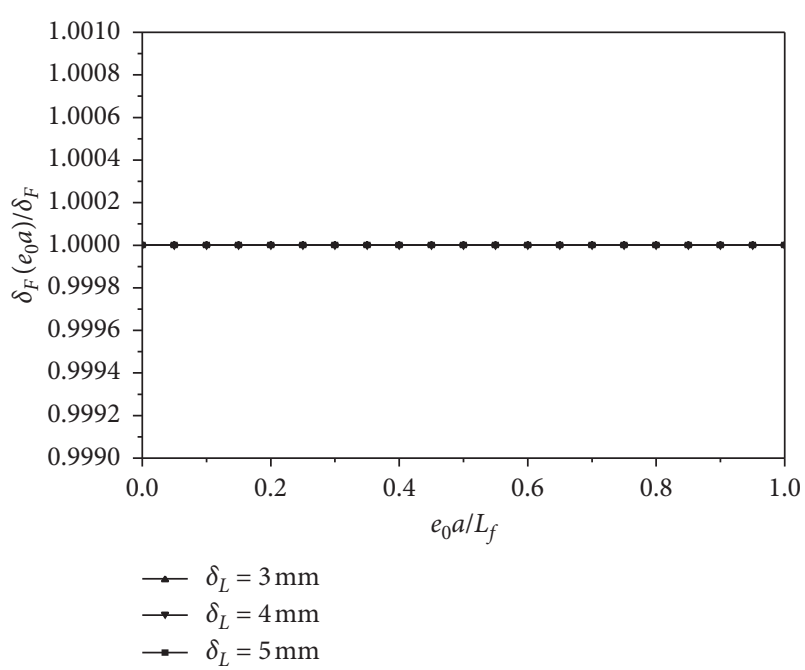

Figure 10: Normalized free-end $\operatorname{slip} \delta_{F}\left(e_{0} a\right)$ for various values of $e_{0} a / L_{f}$ and representative values of $\delta_{L}$ when the frictional stage was the only bond stage acting on the FRP bar.

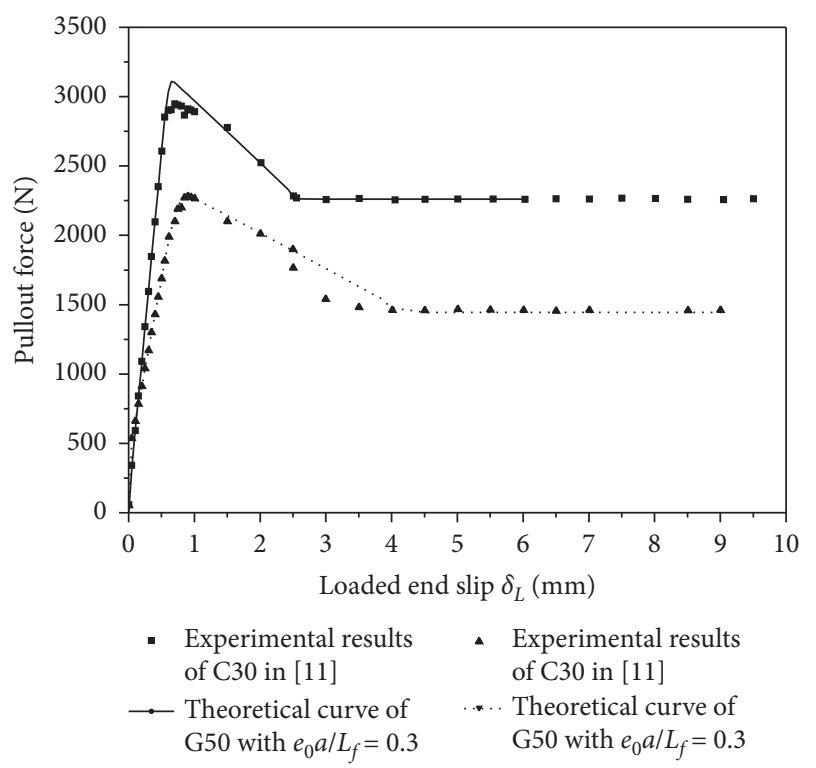

Figure 11: Comparison between the theoretical and experimental $F-\delta_{L}$ relationships for the deformed FRP bars.

experiments and that determined by the nonlocal bond model $\left(e_{0} a / L_{f}=0.3\right)$ are compared in Figure 11. Figures 12 and 13 show the experimental and calculated values of the pullout force for the CFRP and GFRP bars with an imposed slip of $\delta_{L}$, respectively.

Similar to the classical elastic model, a three-stage (ascending, descending, and stationary stages) linear relationship exists between the pullout force $F$ and imposed slip $\delta_{L}$ under the nonlocal model, as shown in Figure 11. When the maximum pullout force occurs during the debonding process, the loaded end slip is $\delta_{1}<\delta_{L}<\delta_{2}$. Consequently, the value is reduced, and the corresponding slip is small, which is attributable to the influence of the nonlocal parameter.

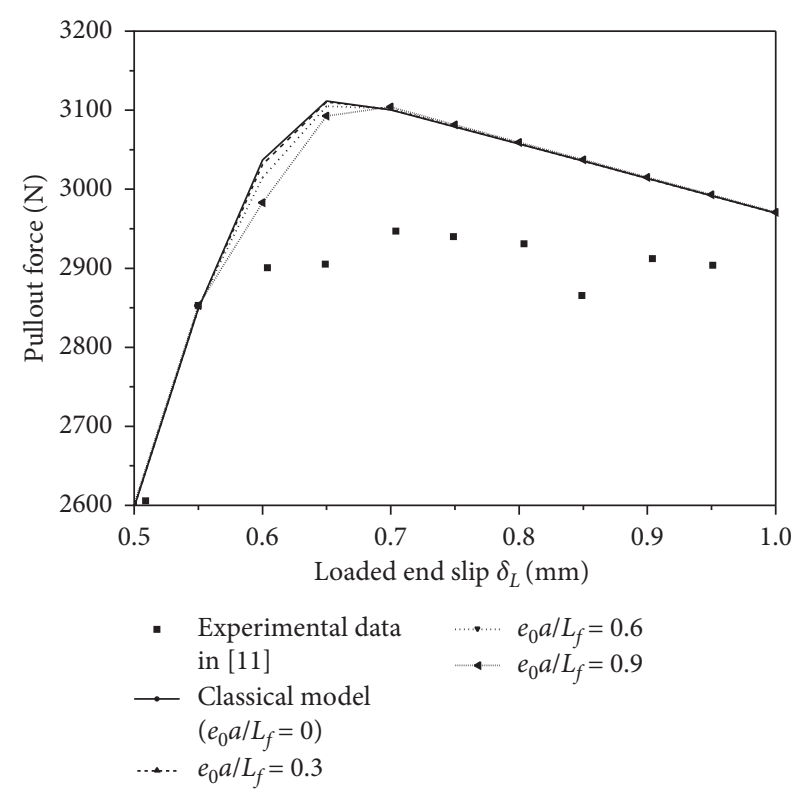

FIGURE 12: Pullout force versus loaded end slip for deformed CFRP bars.

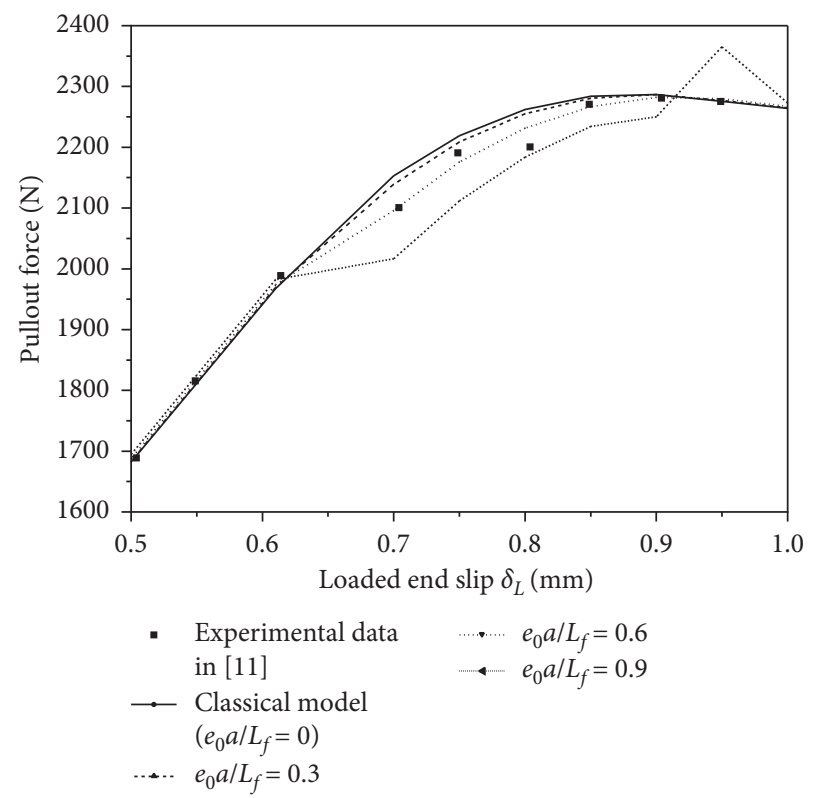

FIGURE 13: Pullout force versus loaded end slip for deformed GFRP bars.

Hence, because of the nonlocal effect on the slip over the bond length, the pullout force is inevitably affected. Figures 12 and 13 show that the maximum load decreases due to nonlocal effects, whereas the surrounding values increase slightly. The nonlocal parameters have a discrete effect and are closer to the experimental values. To determine suitable nonlocal parameters for different types of FRP bars, the corresponding experimental values must be reviewed. For the two FRP bars discussed in the case, the nonlocal parameter of the CFRP bar is 0.9 and that of the GFRP bar is 
0.6. In short, comparing the experimental results of FRP pullout in [11], it is known that the results predicted by the proposed nonlocal model are accurate.

\section{Conclusion}

The theoretical analysis of the debonding of FRP with a nonlocal model allows us to have a deeper understanding of the bonding mechanism of FRP bars and ECC. Inspired by Eringen's nonlocal theory, the proposed nonlocal model considers the influence of the deformation variables on the bonding stress in a certain area of the research site, which is not available in the existing models. When the nonlocal parameter $e_{0} a=0$, the second-order differential governing equation over the bond length of the FRP bar, which is based on the nonlocal elastic model, degenerates into existing classical model, as demonstrated in $[11,12]$. Substituting the bond stress-slip relationship into the governing equation, the solution $\delta(x)$ is an expression containing nonlocal parameters. Affected by these nonlocal parameters, the slip of the elastic stage increases and decreases in the softening stage but does not change in the frictional stage. Because the nonlocal parameter mainly affects the first two stages of the debonding process, the theoretically calculated pullout force is reduced and is more consistent with the experimental data. Therefore, it is more convincing and more accurate to analyze the bond behavior of FRP bars with a nonlocal model. However, the nonlocal parameters are not uniform for different types of FRP bars.

\section{Data Availability}

All data used to support the findings in this study are included within the article.

\section{Conflicts of Interest}

The authors declare that they have no conflicts of interest.

\section{Acknowledgments}

This work was financially supported by the Natural Science Foundation (Project 51868049), Jiangxi Provincial Department of Science and Technology (2013BBE50044, 2016BAB216107, KJLD12048, GJJ-161120, and GJJ180957), National College Student Innovation and Entrepreneurship Training Program (201611319007) and GanPo 555 Talents Program of Jiangxi Province.

\section{References}

[1] C. Lu, V. C. Li, and C. K. Y. Leung, "Flaw characterization and correlation with cracking strength in engineered cementitious composites (ECC)," Cement and Concrete Research, vol. 107, no. 5, pp. 64-74, 2018.

[2] Y. Zheng, C. H. Li, J. B. Yang, and C. Sun, "Influence of arching action on shear behaviour of laterally restrained concrete slabs reinforced with GFRP bars," Composite Structures, vol. 132, no. 11, pp. 20-34, 2015.

[3] T. Liu, Y. Xiao, J. Yang, and B. S. Chen, "CFRP strip cable retrofit of RC frame for collapse resistance," Journal of
Composites for Construction, vol. 21, no. 1, Article ID 04016067, 2017.

[4] M. Elchalakani, G. Ma, F. Aslani, and W. Duan, "Design of GFRP-reinforced rectangular concrete columns under eccentric axial loading," Magazine of Concrete Research, vol. 69, no. 17, pp. 865-877, 2017.

[5] L. Xia and Y. Zheng, "Deep embedment (DE) FRP shear strengthening of concrete bridge slabs under loads close to supports," Applied Sciences, vol. 8, no. 5, pp. 721-729, 2018.

[6] L. J. Malvar, "Tensile and bond properties of GFRP reinforcing bars," ACI Materials Journal, vol. 92, no. 3, pp. 276-285, 1995.

[7] E. Cosenza, G. Manfredi, and R. Realfonzo, "Behavior and modeling of bond of FRP rebars to concrete," Journal of Composites for Construction, vol. 1, no. 2, pp. 40-51, 1997.

[8] R. Eligehausen, E. P. Popov, and V. V. Bertero, Local Bond Stress-Slip Relationships of Deformed Bars under Generalized Excitations, University of California, Oakland, CA, USA, 1983.

[9] B. Zhang, B. Benmokrane, and A. Chennouf, "Prediction of tensile capacity of bond anchorages for FRP tendons," Journal of Composites for Construction, vol. 4, no. 2, pp. 39-47, 2000.

[10] F. Li, Q. L. Zhao, H. S. Chen, J. Q. Wang, and J. H. Duan, "Prediction of tensile capacity based on cohesive zone model of bond anchorage for fiber-reinforce dpolymer tendon," Composite Structures, vol. 92, no. 10, pp. 2400-2405, 2010.

[11] Y. Mi, Experimental and Theoretical Study on Behavior between FRP Bar and ECC: Jiangsu Construction, Southeast University, Nanjing, China, 2015.

[12] H. Mazaheripour, J. A. Barros, J. Senacruz, and F. Soltanzadeh, "Analytical bond model for GFRP bars to steel fiber reinforced self-compacting concrete," Journal of Composites for Construction, vol. 17, no. 6, 2013.

[13] A. Wegner and J. L. Wegner, "Nonlocal continuum field theories," Applied Mechanics Reviews, vol. 56, no. 2, pp. B20-B22, 2003.

[14] W.-P. Liu, M.-F. Fu, and X.-Y. Luo, "Nonlocal friction analysis of grouting bolt in rock," Chinese Quarterly of Mechanics, vol. 26, no. 2, pp. 280-285, 2005.

[15] W.-P. Liu, M.-F. Fu, and X.-Y. Luo, "Nonlocal friction analysis of wholly grouted anchor," Chinese Quarterly of Mechanics, vol. 29, no. 3, pp. 442-447, 2008.

[16] X.-J. Xu, M.-L. Zheng, and X.-C. Wang, "On vibrations of nonlocal rods: boundary conditions, exact solutions and their asymptotics," International Journal of Engineering Science, vol. 119, no. 10, pp. 217-231, 2017.

[17] E. Zarezadeh, V. Hosseini, and V. Hadi, "Torsional vibration of functionally graded nano-rod under magnetic field supported by a generalized torsional foundation based on nonlocal elasticity theory," Mechanics Based Design of Structures and Machines, vol. 48, no. 4, pp. 1-16, 2020.

[18] R. Barretta, S. A. Faghidian, and R. Luciano, "Longitudinal vibrations of nano-rods by stress-driven integral elasticity," Mechanics of Advanced Materials and Structures, vol. 26, no. 15, pp. 1307-1315, 2019.

[19] Z. Zhang, C. M. Wang, and N. Challamel, “Eringen's lengthscale coefficients for vibration and buckling of nonlocal rectangular plates with simply supported edges," Journal of Engineering Mechanics, vol. 141, no. 2, 2015.

[20] R. Barretta, S. A. Fazelzadeh, L. Feo, E. Ghavanloo, and R. Luciano, "Nonlocal inflected nano-beams: a stress-driven approach of bi-helmholtz type," Composite Structures, vol. 200, pp. 239-245, 2018. 
[21] A. Apuzzo, R. Barretta, F. Fabbrocino, and R. Penna, "Axial and torsional free vibrations of elastic nano-beams by stressdriven two-phase elasticity," Journal of Applied and Computational Mechanics, vol. 5, no. 2, pp. 402-413, 2019.

[22] N. Challamel, F. Hache, I. Elishakoff, and C. M. Wang, "Buckling and vibrations of microstructured rectangular plates considering phenomenological and lattice-based nonlocal continuum models," Composite Structures, vol. 149, no. 8, pp. 145-156, 2016.

[23] N. Despotovic, "Stability and vibration of a nanoplate under body force using nonlocal elasticity theory," Acta Mechanica, vol. 229, no. 1, pp. 273-284, 2018.

[24] R. Barretta, S. A. Faghidian, and F. Marotti De Sciarra, "Stressdriven nonlocal integral elasticity for axisymmetric nanoplates," International Journal of Engineering Science, vol. 136, no. 5, pp. 38-52, 2019.

[25] B. Di, J. Wang, H. Li, J. Zheng, Y. Zheng, and G. Song, "Investigation of bonding behavior of FRP and steel bars in self-compacting concrete structures using acoustic emission method," Sensors, vol. 19, no. 1, pp. 159-165, 2019.

[26] N. Saleh, A. Ashour, D. Lam, and T. Sheehan, "Experimental investigation of bond behaviour of two common GFRP bar types in high-strength concrete," Construction and Building Materials, vol. 201, no. 4, pp. 610-622, 2019.

[27] A. C. Eringen, "Nonlocal polar elastic continua," International Journal of Engineering Science, vol. 10, no. 1, pp. 1-16, 1972.

[28] A. C. Eringen and D. G. B. Edelen, "On nonlocal elasticity," International Journal of Engineering Science, vol. 10, no. 3, pp. 233-248, 1972.

[29] X. Zhu and L. Li, "Longitudinal and torsional vibrations of size-dependent rods via nonlocal integral elasticity," International Journal of Mechanical Sciences, vol. 133, pp. 639-650, 2017.

[30] Y. P. Zhang, N. Challamel, C. M. Wang, and H. Zhang, "Comparison of nano-plate bending behaviour by eringen nonlocal plate, hencky bar-net and continualised nonlocal plate models," Acta Mechanica, vol. 230, no. 3, pp. 885-907, 2019.

[31] B. Alireza and C. X. Yang, "Vibration analysis of rotating rods based on the nonlocal elasticity theory and coupled displacement field," Microsystem Technologies, vol. 25, no. 3, pp. 1077-1085, 2019.

[32] V. Bianco, J. A. Barros, and G. Monti, "Bond model of NSMFRP strips in the context of the shear strengthening of RC beams," Journal of Structural Engineering, vol. 135, no. 6, pp. 619-631, 2009.

[33] E. Benvenuti and A. Simone, "One-dimensional nonlocal and gradient elasticity: closed-form solution and size effect," Mechanics Research Communications, vol. 48, no. 2, pp. 4651, 2013. 